\title{
BMJ Open Patients recording clinical encounters: a path to empowerment? Assessment by mixed methods
}

\author{
Glyn Elwyn, Paul James Barr, Stuart W Grande
}

To cite: Elwyn G, Barr PJ, Grande SW. Patients recording clinical encounters: a path to empowerment? Assessment by mixed methods. BMJ Open 2015;5: e008566. doi:10.1136/ bmjopen-2015-008566

- Prepublication history and additional material is available. To view please visit the journal (http://dx.doi.org/ 10.1136/bmjopen-2015008566).

Received 21 April 2015 Revised 29 June 2015 Accepted 30 June 2015
CrossMark

The Preference Laboratory, The Dartmouth Institute for Health Policy and Clinical Practice, Dartmouth College, Hanover, New Hampshire, USA

Correspondence to Professor Glyn Elwyn; glynelwyn@gmail.com

\section{ABSTRACT}

Objective: To examine the motivations of patients recording clinical encounters, covertly or otherwise, and why some do not wish to record encounters.

Design: Mixed-methods analysis of survey data and nested semistructured interviews.

Setting: Survey to UK audience, using social media and radio broadcast.

Participants: 168 survey respondents, of whom 161 were 18 years of age or older (130 completions). Of the 56 participants who agreed to be contacted, we included data from 17 interviews.

Results: 19 (15\%) respondents indicated having secretly recorded a clinical encounter and $14(11 \%)$ were aware of someone who had secretly recorded a clinical encounter. $45(35 \%)$ said they would consider recording secretly and $44(34 \%)$ said they would record after asking permission. Totally, $69 \%$ of respondents indicated their desire to record clinical encounters, split equally between wanting to do so covertly or with permission. Thematic analysis of the interviews showed that most patients are motivated by the wish to replay, relisten and share the recording with others. Some are also motivated by the idea of owning a personal record, and its potential use as verification of a poor healthcare experience. The rationale for permission seeking was based on the wish to prioritise a trusting relationship with a health professional. Those who preferred to record covertly described a pre-existing lack of trust, a fear that recording would be denied, and a concern that an affronted clinician would deny them access to future care. There was a general wish that recording should be facilitated. Conclusions: Patients' prime motivation for recording is to enhance their experience of care, and to share it with others. Patients know that recording challenges the 'ceremonial order of the clinic', and so some decide to act covertly. Patients wanted clearer, more permissive policies to be developed.

\section{INTRODUCTION}

Mobile technology has become pervasive; it is no surprise that it has found its way into medical encounters, with reports of patients recording clinical encounters using either smartphones, or other devices. Some ask permission to record, while others do it covertly. ${ }^{1}$ The behaviour is new, facilitated by

\section{Strengths and limitations of this study}

This study is the first to estimate the extent to which patient recording of medical encounters, covertly or openly, is occurring in the UK, and examines the motivations to do so.

- The mixed-methods design is a strength of this project.

- A convenience sample was used, which limits the generalisability of the results.

- Themes derived from patient interviews were triangulated with open comments made on the survey.

devices that make it easy. It may also indicate the development of a new attitude towards what has been called the 'ceremonial order of the clinic', ${ }^{2}$ challenging the established etiquette of a deferential and subservient patient norm.

There are studies of clinicians deciding to offer recordings to patients, particularly in paediatrics and in oncology, where complex, emotional subjects are discussed, and information given that is especially difficult to retain. A recent review showed that patients valued the ability to relisten to the recordings, often doing so more than once, as well as being able to share recordings with their family. ${ }^{3}$ Patient recall is clearly enhanced by having access to recordings. ${ }^{3}$ A more recent study also found statistically significant reductions in decisional regret for patients with access to recordings. ${ }^{4}$ These benefits could be of value to patients, particularly to those with low literacy, although there is a lack of research on this issue. ${ }^{3} 5$ In mental health and family medicine settings, recordings have been used for clinical training. Where recordings have been shared with patients, their use as adjuncts to therapy has been reported. ${ }^{6}$

Despite the documented benefits associated with clinicians offering recordings to patients, routine recording of clinical encounters is uncommon. Now patients are deciding to record encounters themselves, 
some doing so covertly. ${ }^{7}$ Clinicians are becoming aware of the possibility of being recorded and are concerned that the recordings, especially those that are covert, would be used for litigation purposes. ${ }^{7}$ Policy makers have begun, for the first time, to provide guidance to patients who are considering covert recording. ${ }^{8}$

Although the topic of covert recording has been the subject of recent debate, ${ }^{19}$ we could find no research that has investigated the phenomenon of patients deciding to record their own clinical encounters. The aim of this study was to explore this behaviour, to estimate to what extent it is occurring or is desired, and to understand more about why individuals are motivated to record and how they navigate the decision to do so by seeking permission or by acting covertly.

\section{METHOD}

\section{Survey design and participants}

We administered a cross-sectional survey online, after an interview broadcast on BBC Radio 4 (8 July 2014). In the programme, one of the study authors (GE) talked about the pros and cons of patients recording their clinical encounters. The opportunity to complete a survey about this topic was announced and advertised on the programme website, and through social media. Respondents over the age of 18 were asked three closed-response questions about their experience and views of recording encounters with a health professional: (1) Have you ever secretly recorded your encounter with a health professional? (2) Would you consider secretly recording your encounter? (3) Would you like your clinic to allow you to record your encounters? We included questions about age, gender, education, country of residence and whether English was the only language spoken at home, and space was given for further comments.

\section{Quantitative data analysis}

Categorical responses of respondents from the UK were summarised. Where appropriate, Pearson's $\chi^{2}$ test of independence was used to identify statistical association between categorical variables. Where cell counts were under five, we used Fisher's exact tests. Hypotheses generating multiple logistic regression analyses were conducted to explore respondent characteristics associated with the act of covert recording, compared with all other respondents. We also conducted an analysis comparing the characteristics of individuals who would record a medical encounter with permission to those who would covertly record. All analyses were adjusted for age, gender, language spoken at home and education. Analyses were conducted using STATA, V.13.0 (StataCorp, College Station, Texas, USA).

\section{Qualitative interviews}

We contacted respondents who had provided an email address in the survey and conducted semistructured interviews with consenting participants using an agreed schedule (see online supplementary appendix S1). We purposefully sampled respondents based on survey responses: (1) have covertly recorded; (2) would covertly record; (3) would only record with clinician's permission; and (4) have no interest in recording.

We developed the interview schedule a priori, making modifications based on the respondents' experience of covert recording, or willingness to either record covertly, or with permission, or not to record at all. The interview covered the following topics: respondents' experience of recording or willingness to record, and their motivations do so covertly, with permission, or not at all; perceived benefits and possible negative consequences of recording, both overt and covert; and the consequences and experiences of requesting permission to record. Attention was given to the issues raised at preceding interviews, enabling further probing into salient topics and concerns, consistent with a grounded theory approach. All interviews were conducted over the telephone, recorded and transcribed.

\section{Data analysis}

Before embarking on qualitative analysis of the interview transcripts, two researchers (SWG and PJB) met and developed an initial codebook, based on the interview questions. ${ }^{10}$ This process informed a thematic analysis of interview transcripts where initial codes were grouped by salient themes. Independent coding was completed with the initial codebook. Emergent codes were added, and existing codes revised where necessary. PJB and SWG met to discuss and assess potential additions to the codebook; disagreements were discussed and resolved. A second coding process was undertaken to apply the revised codebook to the data. Codes, memos and short narrative summations of data were entered into a spreadsheet for further discussion with a member of the research team who had also read the transcripts (GE). By critically reviewing the codes and associated memos, the data were categorised using a conceptual mapping process. ${ }^{10}$ We checked the categorisation by comparing the open-text survey comments to the interview data. ${ }^{11}$

\section{RESULTS}

A total of 168 individuals responded to the survey. Seven were under 18 years old, and therefore ineligible. Of the 161 eligible respondents, 130 completed the survey. There were no significant differences in gender, age or educational attainment between individuals who completed the survey and those who did not. A description of respondent characteristics can be found in table 1 .

\section{Do people secretly record their medical encounters?}

Of the 130 complete respondents, 128 answered the questions regarding their experience and views on covertly recording a visit with a health professional (table 2). In this sample, covert recording had been performed, or known about, by $33(26 \%)$ respondents. 
Table 1 Respondent characteristics $(n=130)$

\begin{tabular}{|c|c|}
\hline Survey item & $\begin{array}{l}\text { Respondent } \\
\text { totals (\%), N }\end{array}$ \\
\hline \multicolumn{2}{|l|}{ Gender } \\
\hline Male & $55(44)$ \\
\hline Female & $70(56)$ \\
\hline Other & $1(1)$ \\
\hline \multicolumn{2}{|l|}{ Age (years) } \\
\hline $18-40$ & $53(41)$ \\
\hline $41-60$ & $54(42)$ \\
\hline$>60$ & $23(18)$ \\
\hline \multicolumn{2}{|l|}{ Education } \\
\hline $\begin{array}{l}\text { One or more General Certificate of } \\
\text { Secondary Education or O levels }\end{array}$ & $5(4)$ \\
\hline $\begin{array}{l}\text { Apprenticeship or other related } \\
\text { qualification }\end{array}$ & $4(3)$ \\
\hline One or more A levels & $6(5)$ \\
\hline $\begin{array}{l}\text { Degree or higher professional } \\
\text { qualification }\end{array}$ & $110(87)$ \\
\hline Left school with no formal qualifications & $2(2)$ \\
\hline \multicolumn{2}{|l|}{ Country of residence } \\
\hline England & $86(67)$ \\
\hline Northern Ireland & $8(6)$ \\
\hline Scotland & $3(2)$ \\
\hline Wales & $7(6)$ \\
\hline Other & 24 (19) \\
\hline \multicolumn{2}{|c|}{ Language other than English spoken at home? } \\
\hline Yes & $20(16 \%)$ \\
\hline
\end{tabular}

A total of $19(15 \%)$ respondents reported secretly recording a medical encounter, with a further $14(11 \%)$ respondents reporting that they personally know of someone who has secretly recorded an encounter. When asked if they would consider recording a medical visit with a health professional, $45(35 \%)$ respondents stated that they would, and a further $44(34 \%)$ indicated a willingness to record only after asking the clinician for permission. Finally, 98 (77\%) respondents indicated that they would like their clinic to allow recordings of medical encounters.

\section{Recording covertly or with permission}

Multiple logistic regression analysis indicated that, among respondents, individuals who reported making a covert recording were more likely to be male, OR 3.6 (95\% CI 1.16 to $11 ; \mathrm{p}=0.03$ ) and have less than a university education; OR 5.5 times (95\% CI 1.35 to 22.4; $\mathrm{p}=0.02)$. A second analysis indicated that individuals who would only record with permission from the clinician, compared with those who would covertly record, were more likely to have a university education; OR 11.1 (95\% CI 2.1 to $60.6 ; \mathrm{p}=0.004)$.

\section{Qualitative analysis}

Of the 130 respondents who completed the survey, 56 agreed to be contacted. Of those 56, 21 consented and 18 were interviewed. We excluded data from one
Table 2 Experience and views on patients secretly recording encounters

Respondent totals (\%), N

Have you ever secretly recorded a visit to a doctor or another medical professional?

Yes

No, but I know someone who has

Would you consider secretly recording a visit to a doctor or other health professional?

Yes, I would consider secretly recording 45 (35)

a visit

No, but I would consider recording a visit 44 (34) after asking permission

No, I have no interest in recording a visit 39 (31)

Would you like your clinic to allow you to record visits with a doctor or another health professional?

Yes

$98(77)$

No

$29(23)$

respondent who was not from the UK. We included data from 17 interviews, 10 women and 7 men, all of whom had college (or higher) levels of education; $70 \%$ were 41 years or older and all spoke English at home, save for one individual (for details, see online supplementary appendix S2). Three of the interviewees had covertly recorded in the past, five interviewees would consider secretly recording, seven interviewees would only record with permission and two interviewees would not record. Figure 1 provides a thematic representation of the interview data.

It was evident that the availability of digital technology had, to a large extent, facilitated patients to consider recording clinical encounters; as one individual said: "we've all got devices that are portable and easy to record with" (interviewee 1). Although not all patients will want to make use of the capability, smartphones and other devices can be used with minimal disruption, making covert recording possible. Patients described their motivations to record, and their rationale for either asking permission or acting covertly. They also described how they made use of such recordings, including the associated benefits and concerns. A recurring concern was that recording would violate the etiquette expected in clinical encounters, a deviation from the passive role of the patient. Consequently, many patients volunteered that the solution to this tension would be to 'normalise' the behaviour, to make it part of usual practice. After the interview data were analysed, we compared our findings to the 76 open-text comments in the survey, and found no new themes.

\section{Motivations to record}

We ascertained five prominent reasons that motivated patients to record clinical encounters. The chief 


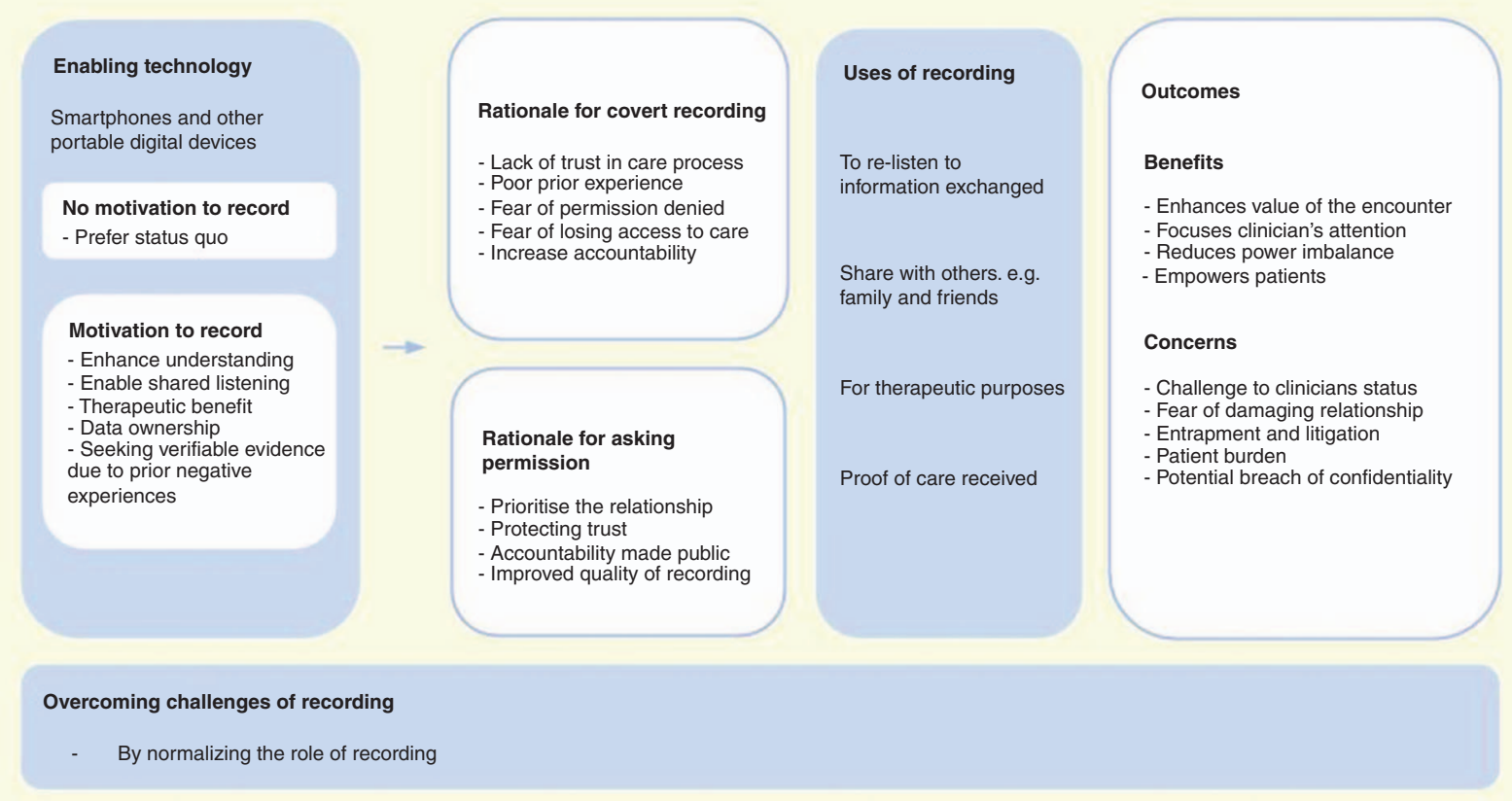

Figure 1 Thematic data representation.

motivation for patients to record was the desire to enhance their understanding of the encounter and, in addition, to share their experience of the encounter with others, particularly when the problems and treatments were complex. There was one instance of a patient describing a therapeutic motivation, where relistening to the encounter was viewed as an additional and complementary therapeutic input. The less explicitly stated motivations were to have a sense of data ownership, that the experience was somehow more tangible by being on record, acting essentially as a "backup for my brain" (interviewee 17), and was in their possession: "So my real motivation for doing the recordings was so that I had a record of what they were actually doing, what they were saying" (interviewee 7). In some instances, this sense of ownership was motivated by prior negative experiences, and the wish to have verifiable evidence of such an experience, should it recur.

Once a patient has decided to record an encounter, they come to a crossroads, 'Should I record covertly or with permission?'.

\section{Rationale for covert recording}

Decisions to record covertly were based on concerns about negative consequences. Interviewees keen to obtain a recording had considered asking for permission, yet had acted covertly due to a fear of being denied permission. Interviewees felt it was easier "to apologize later" rather than "deal with the refusal" (interviewee 14). A interviewee who was also a clinician, also acknowledged this fear: "I think it's quite possible that my clients might have recorded something, an interview with me, without telling me, possibly if they thought I might say no" (interviewee 2).

Fear of denial was related to the worry that clinicians would be affronted by requests to record, to the point of asking patients to leave their care, a particular concern for those living in rural areas with limited options. One interviewee started out recording with permission, but after "being threatened with removal from the practice" (interviewee 8) began to record covertly.

Another factor leading to covert recording was experiencing "jaw-droppingly awful treatment" (interviewee 8), and wanting to have evidence of such an event. Interviewees felt that without such evidence, it was a situation of "his word versus yours" (interviewee 9), and as "the doctor can never be wrong" (interviewee 9), it was necessary to have "actual tape recorded evidence...to protect yourself [the patient]" (interviewee 17).

One interviewee mentioned an experience of using the recording as evidence of bad care and said that it had led to improvement in the quality of further encounters:" $[\mathrm{I}]$ put in the complaint, [and] that I [the patient] have a tape recording of the conversation". When asked about the clinic's reaction, the interviewee stated that "no mention was made [to the recording] in the reply", and since the problem had been placed, that "treatment there has been exemplary" (interviewee 14).

\section{Rationale for asking permission}

The majority of interviewees indicated a desire to record with permission. Maintaining and protecting the relationship with their clinician was a priority: "It's a real partnership thing, isn't it?" (interviewee 16). They feared that covertly recording an encounter "would be a 
breach of trust" (interviewee 12) between the patient and clinician, and that as a patient, "you owe the clinician an explanation" (interviewee 13) for wanting to record. Interviewees felt like recording and "not asking permission would be like subterfuge" (interviewee 1). One interviewee who had been covertly recording indicated discomfort and regret of recording without permission, to the extent that the interviewee was considering a change of stance.

Several interviewees felt that obtaining permission would have more impact, and lead to greater benefits, "...because, as I say, the physician would know that there was accountability" (interviewee 17). Whereas, "If you do it covertly, they [the clinicians] wouldn't know, would they, so I don't think it would change what was said in the room" (interviewee 6). Acting covertly would, they argued, lead to only "getting half of the benefit out of the recording" (interviewee 8). Requesting permission was also viewed as a means of increasing mutual respect: "I think if it was done openly, and with agreement to both parties, I think it could help develop more trust in the relationship" (interviewee 12). In addition, on a purely practical level, gaining permission enables a device to be used openly, facilitating a "...better quality recording" (interviewee 14).

\section{Use of recording}

Those interviewed described four distinct uses of the recordings. Relistening was the prime use, “...to help me better understand what they said, because sometimes they talk so quickly" (interviewee 15). The ability to share the recording with others was very important to many individuals. One mentioned that the recording could be used for therapeutic purposes, particularly if the clinician was prepared to collaborate and support such a goal. The recording could also be used as proof of care received, with the clear implication that such data could constitute evidence of unsatisfactory care, should such a situation occur.

\section{To relisten to information exchanged}

Interviewees who found it difficult to recall clinical encounters were often unable to follow what was said, either because it was unclear, or delivered too quickly. It was widely felt that even though a patient might refer "back to it [the recording] once or twice... [many] just found it useful to have as a reference" (interviewee 7).

\section{Share with others}

A common frustration reported by patients was an inability to give a good account of their clinical encounter. Interviewees acknowledged the significant benefit of: "...bringing people into the process" (interview 4) by replaying the recording. This was viewed as a more reliable way of ensuring that others were able to understand the advice given, and as help to "follow whatever instructions were provided" (interviewee 13).

\section{For therapeutic purposes}

An unexpected use of a recording was to revisit "the emotion of the conversation", to relisten to the "tone of voice" to "get all that reassurance and attachment stuff" (interviewee 5). This therapeutic use of the recording was made possible by the ability to replay the encounter: “...when I listen back, I feel very supported and validated by those little things which I've missed first time round...that sort of reinforces the benefits of the therapy" (interviewee 5).

\section{Proof of care received}

The interviews indicated there was a desire by some to use the recordings as proof of interactions experienced. This was triggered by a sense that without having proof, concerns had too often been dismissed in the past: "I think it could have helped to support my story of what happened" (interviewee 16). Patients reported the need to have verification, and that if they were unsatisfied, their word alone was insufficient: "When you're experiencing poor engagement with your clinician...it [a recording] would be really useful as a kind of evidence" (interviewee 6). A recording was viewed as less open to dispute: "...he was being unsupportive, he said the wrong thing... and here is the proof" (interviewee 5).

\section{Outcomes: benefits}

Four benefits of recording encounters were described. The prime benefit was that of empowerment. As one patient said: "In this context, it shifts the power dynamics. It doesn't revolutionise them, but it makes us less passive" (interviewee 5). Reflecting on the benefit, a patient said, "In the NHS, I felt I had no power. So I just wanted to level the playing field a bit" (interviewee 7). Having a record of the encounter enhanced its value and served multiple purposes. This benefit occurs whether the recording is undertaken covertly or with permission. However, three of the benefits were predicated on the recording being conducted overtly, with the explicit permission of the clinician. Recording openly was viewed as a mechanism to focus the clinician's attention, to reduce the power imbalance and potentially reduce future needs: "I think it's just so important because it doubles or triples the value. Why wouldn't you do it?" (interviewee 5). Patients also noted that the process enhanced their ability to check whether they had explained themselves well, to "actually listen to what I said" (interviewee 17).

\section{Outcomes: concerns}

Multiple concerns were voiced about the act of recording clinical encounters. Some patients were worried about the new burden of owning such data, of having to listen and make sense of the new form of information "...but, of course, that depends on you being able to pick out...the crucial points...pick them out and talk about them" (interview 11). In addition, the behaviour is not only novel, it also cuts across the established 
etiquette of patient-clinician interactions and, in part, questions the established status of the professional as the one who legitimately documents the interaction. There is therefore a clear challenge to status, and this, in turn, leads to patients reporting concern about damaging existing, or potential, professional relationships, or being denied access to care by a clinician who has been angered by the process. One patient worried “...that [the doctor] wasn't being as open and honest, that he would give me a different sort of care, because he would be worried that I was trying to catch him out" (interviewee 12). Concerns were also raised about the potential use of recordings for entrapment, for litigation against the clinician, as well as the possible loss of control of the recordings, and concerns about confidentiality and privacy.

\section{Normalisation}

As the interview data made clear, recording was viewed as a threat to established norms, and despite the willingness of some patients to seek permission, it was viewed as a request that would be viewed negatively by most clinicians. The suggested solution, widely made, was for "people to do this routinely" (interviewee 9), that is, to normalise the process and develop a policy where recording would not only be encouraged, it would be facilitated by the clinic. As one interviewee said: "Maybe they are slowly coming to the realisation that there ought to be nothing wrong with this" (interviewee 8). This strategy was viewed as a way to alleviate most, if not all, the concerns, and to enable the benefits: "if a sound recording was made just as a matter of routine... They'd just be so used to it; it would just be a normal part of their day" (interviewee 14).

Many interviewees contrasted recording with written summaries of the encounter, made by the clinician or by the patient. Some preferred summaries, feeling that they were less burdensome. Others highlighted challenges, such as concerns about the accuracy of summaries and the disruption of trying to "keep up" (interviewee 5), and difficult to catch "new long words..." (interview 17).

\section{DISCUSSION}

\section{Principal findings}

The portability and multiple capabilities of smartphones, or similar digital devices, has conferred increasing agency on some patients, who have decided to seek a more tangible record of their healthcare encounters. This is supported by the finding that $19(15 \%)$ of our survey respondents indicated that they have secretly recorded a medical encounter, while $89(69 \%)$ respondents indicated their desire to record clinical encounters, split equally between wanting to do so covertly or with permission. The overarching motivations to record resided in the ability to relisten to the medical encounter on their own or with others, to enhance recall and understanding of health information. Some patients were motivated by viewing recording as a potential means of obtaining verifiable evidence of poor care experienced.

We identified a subset of motivations that influenced the patient's decision to record either covertly or with permission. The decision to covertly record was associated with a fear of being denied permission to record, or where patients had prior experiences of poor quality care: the prospect of having verifiable evidence. Whereas, recording with permission was associated with a desire to maintain, even enhance, the relationship and trust between clinician and patient.

Our analysis tentatively suggests that individuals with less education were more likely to record covertly, indicative perhaps of a perceived stigma or disempowerment. Some patients were fearful that seeking permission would be counterproductive, and concerned that permission would be denied and the relationship damaged, perhaps beyond repair. These patients, who were a minority viewpoint in the sample surveyed and interviewed, were prepared to record covertly.

Generally, patients cited many benefits, with the underpinning rationale that recording the encounter was a clear signal of empowerment, enhancing the value of the encounter, especially when permission was sought, thereby ensuring that clinicians were made aware of the process. There were also concerns: patients worried that recording might disturb established norms, and be at odds with the expected etiquette of being subservient and passive. On the professional side, there were concerns that recordings could provide data for possible litigation. To alleviate these concerns, many suggested that the process of recording clinical encounters should be normalised and become part of routine practice.

\section{Weaknesses and strengths}

The survey we conducted was not representative of the UK population: $87 \%$ had a college education or higher, and were recruited from a radio audience or from social media. Respondents represent those who wanted to voice their opinion on this subject. Yet, we were able to gather a range of responses to the idea of recording clinical encounters, with and without permission. Examining this issue in more depth by combining a survey and interviews enabled us to examine motivations, uses, concerns and benefits, and to uncover multiple perspectives.

\section{Results in context}

Our search for similar work did not yield comparative empirical studies. Related work that has evaluated clinicians' giving recordings to patients has consistently reported the benefits of increased understanding and better recall. ${ }^{3}$ We identified the potential to use recordings as an adjunct to therapy, supporting findings from a previous study from a mental health setting. ${ }^{6}$ Our analysis revealed the range of patient motivations to record 
as well as novel uses for the recordings. Our research group has analysed reactions of patients and clinicians posted in online media, concluding that the issue generates conflicting views about the legitimacy of the behaviour, especially about covert recording. ${ }^{7}$ We recognise the work in sociology that has drawn attention to power imbalance in clinical encounters ${ }^{12}$ and debates about patient-provider asymmetries. ${ }^{13}$ The recent interest in shared decision-making and patient involvement has led to efforts to modify this asymmetry, and to intervene, for example, with information tools called patient decision aids, ${ }^{14}$ or use of patient activation tools. ${ }^{15}$ These studies have documented effects, but real-world implementation is an uphill effort. Recently, other efforts to increase transparency have been initiated, such as the Open Notes, giving patients the ability to comment on their records, with positive benefits reported. ${ }^{16}$ Having access to a digital copy of the encounter could be the next step.

\section{Implications}

Patients recording encounters does not seem to be a widespread phenomenon, but this data, albeit it from an educated sample of people, does indicate that many patients seem in favour of having access to recordings, at least for some situations. Evidence that some organisations have recognised this comes from examples such as the Oliver Cancer Center in the USA ${ }^{17}$ giving recorders to patients and making the recording process the new 'normal'. Software designed to support the recording of clinical encounters is beginning to emerge. There will be concerns about data security and ownership, so more guidance will be required. It is noteworthy, for instance, that the Care Quality Commission in the UK has published guidance about the use of hidden cameras. ${ }^{8}$

\section{Unanswered questions}

Conducting a larger, more representative survey, would provide more precise information about patient recording, but it is likely that such a snapshot would be transient, and would not add much more to an understanding of motivations and utility. The unanswered question is, how will organisations and clinicians at large react to the concept of recording becoming normalised? Do recordings of the clinical encounter become part of the clinical record? And, if so, what are the ramifications of how such data could be used and accessed?

\section{Twitter Follow Glyn Elwyn at @glynelwyn}

Contributors SWG conducted the qualitative interviews, and contributed to data interpretation and manuscript preparation. PJB contributed to the study design, quantitative and qualitative analysis, and preparation of the manuscript. GE initiated the study, participated in data analysis and prepared the article. He is the guarantor. All the authors, external and internal, had full access to the data (including statistical reports and tables) in the study, and can take responsibility for the integrity of the data and the accuracy of the data analysis.
Funding This research received no specific grant from any funding agency in the public, commercial or not-for-profit sectors.

Competing interests None declared.

Ethics approval Ethical review of the study was conducted by the Center for Protection of Human Subjects, Dartmouth College, CPHS\# STUDY00028222.

Provenance and peer review Not commissioned; externally peer reviewed.

Data sharing statement Consent was not sought from participants to share study data. However, interested parties should contact the study authors to discuss access to de-identified data.

Open Access This is an Open Access article distributed in accordance with the Creative Commons Attribution Non Commercial (CC BY-NC 4.0) license, which permits others to distribute, remix, adapt, build upon this work noncommercially, and license their derivative works on different terms, provided the original work is properly cited and the use is non-commercial. See: http:// creativecommons.org/licenses/by-nc/4.0/

\section{REFERENCES}

1. Elwyn G. 'Patientgate'-digital recordings change everything. BMJ 2014;348:92078.

2. Strong P. The Ceremonial Order of the Clinic. London: Routledge, 1979.

3. Tsulukidze M, Durand MA, Barr PJ, et al. Providing recording of clinical consultation to patients-a highly valued but underutilized intervention: a scoping review. Patient Educ Couns 2014;95:297-304.

4. Good DW, Delaney H, Laird A, et al. Consultation audio-recording reduces long-term decision regret after prostate cancer treatment: a non-randomised comparative cohort study. Surgeon 2015. Published Online First: 27 January 2015.

5. Santo A, Laizner AM, Shohet L. Exploring the value of audiotapes for health literacy: a systematic review. Patient Educ Couns 2005;58:235-43.

6. Shepherd L, Salkovskis PM, Morris M, et al. Recording therapy sessions: an evaluation of patient and therapist reported behaviours, attitudes and preferences. Behav Cogn Psychother 2009;37: 141-50.

7. Tsulukidze M, Grande S, Thompson R, et al. Patients covertly recording clinical encounters: threat or opportunity? A qualitative analysis of online text. PLOS ONE 2015;10:e0125824.

8. Care Quality Commission. Thinking about using a hidden camera or other equipment to monitor someone's care? London: 2015. http:// www.cqc.org.uk/sites/default/files/20150212_public_surveillance_ leaflet_final.pdf (accessed 14 Mar 2015).

9. Elwyn G, Buckman L. Should doctors encourage patients to record consultations? BMJ 2015;350:g7645.

10. Miles M, Huberman A. Qualitative data analysis: an expanded sourcebook. San Francisco: SAGE publications, Inc, 1994.

11. O'Cathain A, Murphy E, Nicholl J. Three techniques for integrating data in mixed methods studies. BMJ 2010;341:c4587.

12. Szasz T, Hollender M. A contribution to the philosophy of medicine: the basic models of the doctor-patient relationship. Arch Intern Med 1956;97:585-92.

13. Maseide P. Possibly abusive, often benign, and always necessary. On power and domination in medical practice. Sociol Heal IIIn 1991;13:545-61.

14. Stacey D, Légaré F, Col NF, et al. Decision aids for people facing health treatment or screening decisions. Cochrane database Syst Rev 2014;(1):CD001431.

15. Kinnersley P, Edwards A, Hood K, et al. Interventions before consultations to help patients address their information needs by encouraging question asking: systematic review. BMJ 2008;337: a485.

16. Delbanco T, Walker J, Bell SK, et al. Inviting patients to read their doctors' notes: a quasi-experimental study and a look ahead. Ann Intern Med 2012;157:461-70.

17. Oliver Cancer Center. Patient Visit Recording Project: Taking the Message and Medicine Home. http://www.utmb.edu/olivercenter/ projects/current/pvr_1.asp (accessed 14 Mar 2015). 